\title{
Comparison of different approaches for bioleaching of a granite-type uranium ore
}

\author{
Gongxin Chen ${ }^{1}$, Zhanxue Sun ${ }^{1, *}$, Yajie $\mathrm{Liu}^{1}$, Jinhui $\mathrm{Liu}^{1}$, Baoqun $\mathrm{Hu}^{1}$, and Hongjun Zhang ${ }^{1}$ \\ ${ }^{1}$ State Key Laboratory of Nuclear Resources and Environment, East China University of Technology, \\ Nanchang 330013, Jiangxi Province, China
}

\begin{abstract}
Uranium bioleaching has been rapidly developed in China during recent years. However, some problems during bioleaching, such as low uranium leaching efficiency for rocks lacking pyrite, remain to be solved. A granite type uranium deposit from southern China was selected for the study of $U$ bioleaching with addition of pyrite. Experiments using four approaches, including (i) pyrite ores mixing with culture, (ii) pyrite tiled on the surface of ores with culture, (iii) no pyrite ores with culture, and (iv) pyrite ores without culture were examined in this study. Results showed that bacteria can improve $U$ leaching efficiency, particularly by adding pyrite into ore. Approach (i) pyrite ores mixing with culture had the highest $U$ concentration and the highest recovery rate of the four approaches. No significant difference was observed between approaches (ii) pyrite tiled on the surface of ores with culture and (iii) no pyrite ores with culture.
\end{abstract}

\section{Introduction}

Bioleaching refers to the mobilization of metal cations from ores by bio-oxidation and complexation processes. This is a new technology for heap or dump leaching of metals such as $\mathrm{Cu}, \mathrm{Au}, \mathrm{U}$ and $\mathrm{Ni}$ from low-grade ores through an economical and eco-friendly manner [1-4]. It has developed rapidly in China for the past two decades. In the early 1990s, the Research Institute of Uranium Mining affiliated to China National Nuclear Corporation carried out an indoor bioleaching test on some $\mathrm{U}$ ores and adopted in situ bioleaching technology for low-grade ores. A successful test of a U bioleaching pilot operation has also been conducted at the industrial scale [5]. In 1993, the Beijing Research Institute of Chemical Engineering and Metallurgy conducted a bioleaching test at Benxi Uranium Mine [6]. Various researchers have investigation bioleaching mechanisms [7-9]. However, some problems, such as low efficiency of $U$ leaching for low pyrite ores or long duration of leaching, still remain [10-11]. Low pyrite content is an unfavourable situation for bioleaching of $U$.

\footnotetext{
* Corresponding author: zhxsun@ecit.cn
} 


\section{Materials and methods}

In a previous study [12], we added pyrite into U ore to supply a sufficient Fe source for bacterial needs. In order to enhance the $U$ leaching rate of ores with a low concentration of pyrite, bioleaching tests of a granite-type $U$ ore with addition of pyrite were carried out in a series experiments. Results of bioleaching with and without additional pyrite demonstrated that a higher rate of $U$ leaching is obtained with $1.5 \mathrm{wt} . \%$ additional pyrite [13]. The primary problem addressed in this study was how to undertake the mixing approach of the exogenous pyrite to the $U$ ore in order to maximize $U$ recovery, i.e., to determine the optimal mode of heap building in order to improve the utilization of pyrite in the leaching system. The average content of $\mathrm{F}$ was 1.69 wt. $\%$ and $\mathrm{CaF}_{2}$ was 2.56 wt. $\%$ in our test. $\mathrm{CaF}_{2}$ is also one of the important acid consuming minerals in bioleaching. It is important to note that a high $\mathrm{CaF}_{2}$ content will increase acid consumption, however, $\mathrm{F}^{-}$will increase gradually during acid leaching and this will seriously affect the growth of bacteria and reduce the activity of the bacteria. Therefore, it is also necessary to improve the resistance ability of bacteria to fluorine by domestication or other means.

\subsection{Uranium Ore}

Uranium ore was obtained from a granite-associated deposit located in southern China. Particle sizes of $U$ ore for column tests were $<8 \mathrm{~mm}$. Analysis indicated that the average $\mathrm{U}$ grade of the ore was 0.17 wt.\%, with $\mathrm{S}$ (II) $<0.56$ wt.\% and pyrite (FeS2) $<1.0$ wt.\%. EMPA study shows that U-bearing minerals are closely related to fluorite and pyrite. It has been observed that the stronger the $U$ mineralization, the greater the abundance of adjacent pyrite as shown in Figure 1(a) and U mineralization developed in small fissures as shown as Figure 1(b).

\subsection{Pyrite}

The pyrite with Fe 41.6 wt.\% and with a particle size of $3 \mathrm{~mm}$ was obtained from Guangdong Yunfu Pyrite Mine Enterprise Group Co., Ltd.

\subsection{Leaching bacteria}

The bacteria used in this experiment, bacteria were L. ferriphilum and At. Caldus as shown in Figure 2. The F tolerance of the bacteria was improved by domestication in the laboratory.

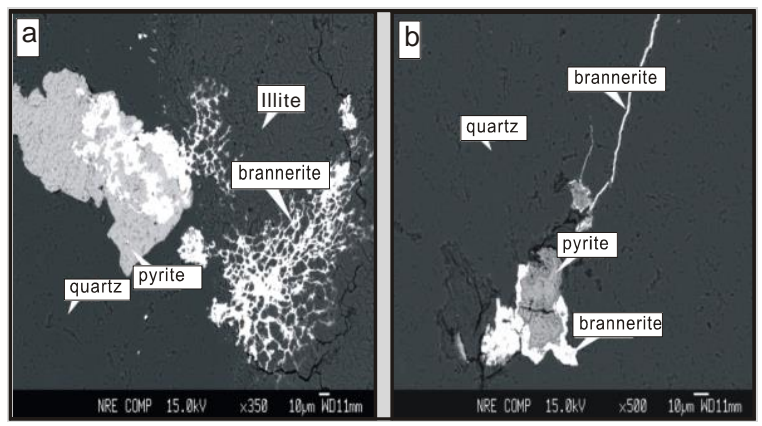

Fig. 1. Backscattered EMPA image of (a) U mineralization around pyrite; (b) fissure-related U mineralization. 


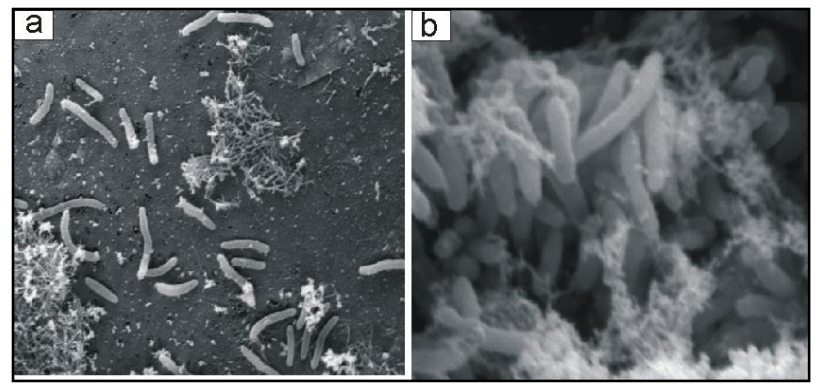

Fig. 2. Composition of bacteria by scanning electon microscopy (a L. ferriphilum and At. Caldus (short rod)(5000x); (b) - At. caldus (10000x)).

\section{Test design and experimental cases}

Pyrite adding approaches were divided into four tests, $0.135 \mathrm{~kg}$ pyrite $+9 \mathrm{~kg}$ ores mixing with culture (ZT1), $0.135 \mathrm{~kg}$ pyrite tiled on the surface of $9 \mathrm{~kg}$ ores with culture (ZT3), no pyrite $+9 \mathrm{~kg}$ ores with culture (ZT5) and $0.135 \mathrm{~kg}$ pyrite $+9 \mathrm{~kg}$ ores without culture (ZT7). The irrigating scheme is 12 hours irrigation and 12 hours residence time per day.

The experimental set up is shown in Figure 3. There are three components to the bioleaching system: 1 - a bacterial culture, 2 - the $U$ leaching reactor, and 3 - the $\mathrm{U}$ adsorption domain and three phases of the $U$ leaching process as shown in Figure 4: $\mathrm{A}$ - the acidification stage, B - the culture inoculation (also called 'bacteria planting') stage, and C - the bioleaching with raffinate stage. Late in the leaching period, ore columns were turned over for better penetration of solution through each column.

During culture cultivation, mixed bacteria were cultured by a continuous culture device with 4 tanks in order to achieve a $\mathrm{Fe}^{2+}$ oxidation rate of $90 \%$ in a short time. The acidity of the irrigation solution was adjusted with commercial $\mathrm{H}_{2} \mathrm{SO}_{4}$ to $\mathrm{pH}=1.8$ for both the acidification stage and bioleaching stage. Acidification of the ores was achieved by decreasing the acidity of the solution $\mathrm{pH}$ below 1.8 and afterwards stabilizing this between 1.8 to 2.0 for 24 hours. Then, an irrigation solution of mature culture with $\mathrm{pH}=1.8$ that contained $>90 \% \mathrm{Fe}^{3+}$ was introduced evenly from the top of column. When the culture was ready for the absorption process, the solution was transferred to the adsorption reactor and and the $U$ it contained was adsorbed by an ion exchange resin. The raffinate released from the adsorption operation was reused for bacterial cultivation in the early stage of bioleaching or directly for irrigation after the middle stage of bioleaching.

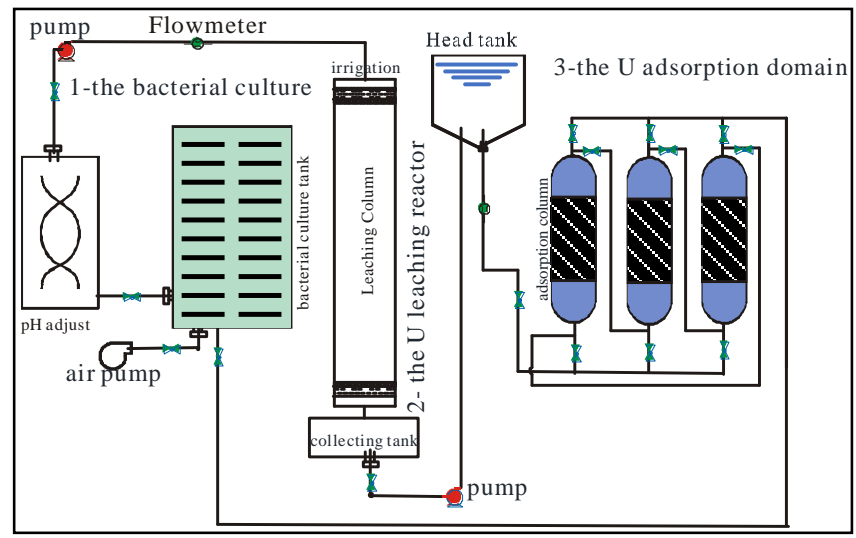

Fig. 3. Schematic of the bioleaching experimental apparatus. 


\section{Experimental results and discussion}

Results of $U$ concentration change and $U$ leaching rate through time for each column are shown in Figure 4. Four peaks of $U$ concentration during the entire $U$ leaching process are observed. The first peak occurs at the beginning of acidification stage when the $\mathrm{U}^{6+}$ is readily dissolved under highly acidic conditions. A second peak is observed on the 4th day of the bacteria planting stage when $\mathrm{U}^{4+}$ is oxidized by $\mathrm{Fe}^{3+}$ in the culture irrigation solution into $\mathrm{U}^{6+}$, except in column ZT7 that is without culture.

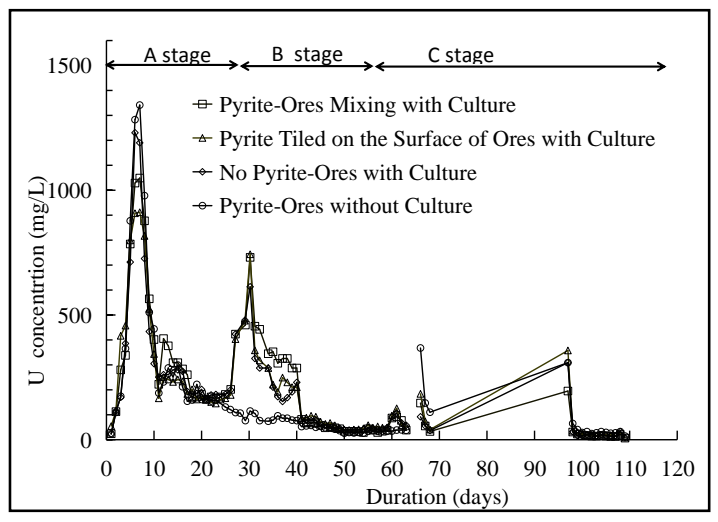

Fig. 4. U concentration in the leachates.

Comparing these four tests (ZT1, ZT3, ZT5 and ZT7), approach (i) pyrite ore mixing with culture (ZT1) yields higher $U$ concentrations after bioleaching than the other three approaches and approach (iv) pyrite ore without culture (ZT7) produces the lowest U concentrations. Approaches (ii) pyrite tiled on the surface of ores with culture (ZT3) and (iii) no pyrite-ores with culture (ZT5) produce similar U concentrations. These results indicate that leaching in the presence of bacteria can improve $U$ yields significantly. In test ZT3, the increase of $U$ concentration was marginally lower than that of test ZT1 because additional pyrite could not distributed evenly with ores and the bacteria could not use pyrite as energy to produce $\mathrm{Fe}^{3+}$ throughout the column at the raffinate irrigation stage. As shown in Figure 5 , the final leaching rates of tests ZT1, ZT3, ZT5 and ZT7 were $93.2 \%, 87.6 \%, 87.2 \%$ and $83.0 \%$, respectively. All results indicated that mixing of additional pyrite with $U$ ore is the better approach for bioleaching and an excess of pyrite is most efficient for $U$ recovery from ores.

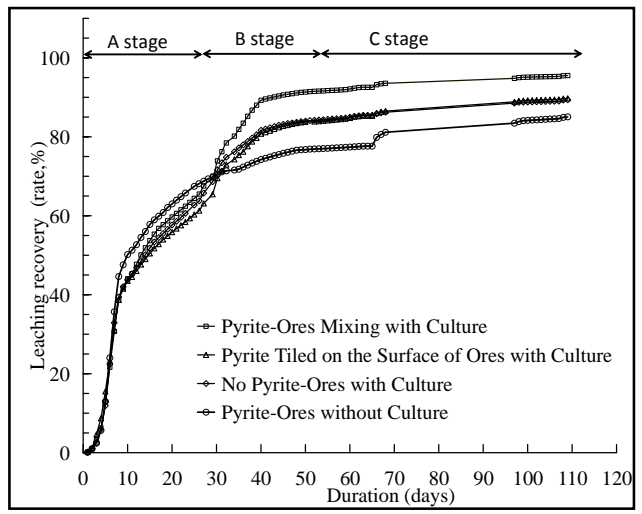

Fig. 5. U recovery (percent of total)). 


\section{Conclusions}

Tests with different pyrite adding approaches, with or without pyrite and with or without culture (ZT1, ZT3, ZT5 and ZT7), were set up with total $9 \mathrm{~kg}$ uranium ore in columns of same sizes and additional pyrite of $1.5 \mathrm{wt} . \%$. Observed leaching rates were $93.2 \%, 87.6 \%$, $87.2 \%$ and $83.0 \%$, respectively, and the total acid consumption rates were around $4 \%$.It is concluded that the mixed culture used in this study can substantially improve U leaching efficiently. In the four tests, pyrite ore without culture (ZT7) produced the lowest U leaching rate compared with the other tests, which indicates that bioleaching enhances chemical leaching and the addition of pyrite to uranium ores of low pyrite content is necessary for efficient $U$ extraction.

Acknowledgments. This work was supported by the National Natural Science Foundation of China (Grant Nos. 4166201541772266 and U1501231), State Key Laboratory of Nuclear Resources And Environment of ECUT (Grant No.Z1508) and Science and Technology Plan Project of Jiangxi Province Science And Technology Department (Grant No. 20133BFB29004).

\section{References}

1. C.L. Brierley, Hydrometal, 104:324-328 (2010)

2. T. Rohwerder, et al., App Microbiol Biotech, 63:239-248 (2003)

3. D. Mishra, et al., Metals Material Int, 11:249-256 (2005)

4. M. Vera, et al., App Microbiol Biotech, 97:7529-41 (2013)

5. Kaiguang $\mathrm{Hu}$, et al., Mining Metal, 12:10-13 (2003)

6. Z. Yijun, et al., Uranium Min Metal, 01:1-5 (2005)

7. A. Cameron Rory, et al., Hydrometal, 97:213-220 (2009)

8. G. R. Mafi, et al., Hydrometal, 106:26-31 (2011)

9. D.F. Haghshenas, et al., Hydrometal, 99:202-208 (2009)

10. Z. Long, et al., Hydrometal, 74:181-187 (2004)

11. L. Xingyu, al., Hydrometal, 95:267-272 (2009)

12. X. Kong and J. Liu., Metal Mine, 4:78-80 (210)

13. Y. Liu et al., Non-Ferrous Met (metallurgy) (in Chinese), 4:38-42 (2016) 